\title{
A Systems Processing Model for Molten Salt Reactors
}

Nuclear Technology

Research and Development

\section{INL-EXT-18-45007}

Prepared for

U.S. Department of Energy Molten Salt Reactors Campaign

Tae Sic Yoo

Idaho National Laboratory June 30, 2018 



\section{DISCLAIMER}

This information was prepared as an account of work sponsored by an agency of the U.S. Government. Neither the U.S. Government nor any agency thereof, nor any of their employees, makes any warranty, expressed or implied, or assumes any legal liability or responsibility for the accuracy, completeness, or usefulness, of any information, apparatus, product, or process disclosed, or represents that its use would not infringe privately owned rights. References herein to any specific commercial product, process, or service by trade name, trade mark, manufacturer, or otherwise, does not necessarily constitute or imply its endorsement, recommendation, or favoring by the U.S. Government or any agency thereof. The views and opinions of authors expressed herein do not necessarily state or reflect those of the U.S. Government or any agency thereof. 



\section{SUMMARY}

The chemistry group within the U.S. Department of Energy Molten Salt Reactor Campaign is developing a model for the molten salt reactor system for assessing the suitability of various used fuel processing schemes. In the long run, the developed model is expected to be a tool for better understanding the interplay between the components of the molten salt reactor system including uranium resources, the molten salt reactor, the used fuel processor (e.g., reprocessing plant), and waste management. In this regard, the report proposes a theoretical framework for integrating the various components of the molten salt reactor system. Rather than being buried in implementation details for seemingly heterogeneous components of the reactor system asking for various modeling techniques, this report proposes to approximate and integrate all components with a unified mathematical framework, a discrete-time linear system. An abstracted molten salt reactor system is given as an example to illustrate the effectiveness of the proposed theoretical framework. A fully developed molten salt reactor system model (based on the proposed framework) is expected to be beneficial for various objectives including the transient and equilibrium analysis of fuel cycle scenarios and the identification of potential technology bottlenecks. 


\section{CONTENTS}

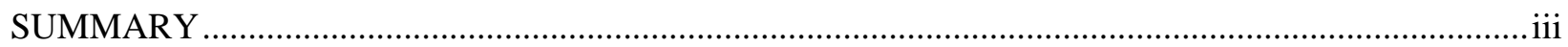

ACRONYMS

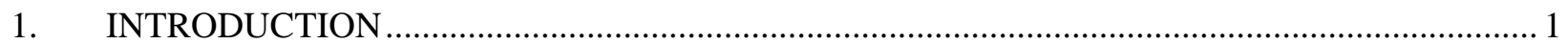

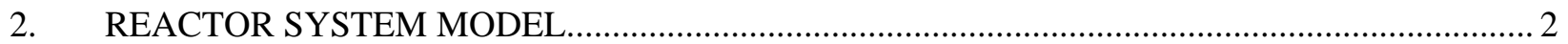

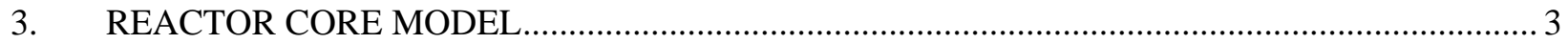

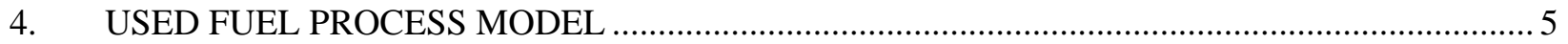

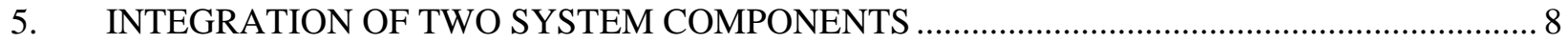

6. ILLUSTRATIVE EXAMPLE OF MODEL INTEGRATION ................................................. 9

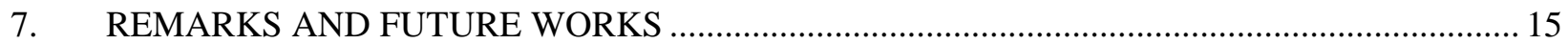

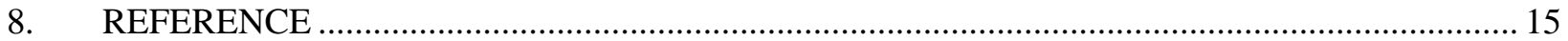

\section{FIGURES}

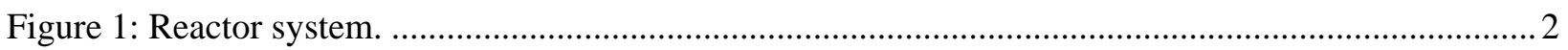

Figure 2. Operation matrices for 1\% reactor inventory discharge scenario.......................................... 12

Figure 3. Operation matrices for $2 \%$ reactor inventory discharge scenario............................................ 13

Figure 4. Operation matrices for $10 \%$ reactor inventory discharge scenario.......................................... 14

\section{TABLES}

Table 1. Steady-state material inventories and flows with 1\% reactor inventory discharge......................13

Table 2. Steady-state material inventories and flows with 2\% reactor inventory discharge...................... 14

Table 3. Steady-state material inventories and flows with 10\% reactor inventory discharge.....................15 


\section{ACRONYMS}

ORNL Oak Ridge National Laboratory

MSR molten salt reactor

UFP used fuel processor 



\section{A SYSTEMS PROCESSING MODEL FOR MOLTEN SALT REACTORS}

\section{INTRODUCTION}

The development of molten salt reactor (MSR) systems has a long history and abundant related literature. A recent overview on various topics related to MSR systems can be found in [1]. A typical MSR system uses molten salt fuel for irradiation. In this system, the reactor discharges a part of the molten salt inventory to the used fuel processor (UFP) for chemical treatment. The UFP treats the discharged used fuel to separate the fission products and feeds the processed fuel back to the reactor along with the exogenous fuel feed to make up the discharged salt from the reactor.

The relevant modeling and simulation literature results are vast and this report does not intend to identify all pertinent results. However, chronological sorting of the literature provides a content trend. The literature is strongly influenced by the technologies available at the time of development and publication. During the early MSR programs at Oak Ridge National Laboratory (ORNL), the integrated neutronic and fuel cycle analysis tools [2] were created and the associated processing plant codes [3] were developed. Including [2, 3], the early analyses of the MSR system focus on the equilibrium state of the reactor where fission products accumulates in the fuel salt as the fuel salt undergoes irradiation [4-8]. With the advancement of powerful simulation tools, recent analysis focus has shifted to the isotopic composition variation of the fuel salt from the startup to the equilibrium condition of the MSR system by modifying neutron transport and depletion codes to account for the continuous feeds and removals in the MSR systems [9-21].

Note that, traditionally, fuel cycle simulation has focused on refinement of the reactor side while adopting a simplified used fuel processing assumption (often idealized) on the separation performance. In terms of the analysis of solid-fueled systems, where the fission products, actinides, and activated isotopes physically remain within a fuel rod or assembly for an extended time period, the assumed performance of the used fuel process facility has been widely overlooked as the reactor operation is loosely coupled with the used fuel process with a significant time delay such as the required used fuel cooling time. However, the performance of the MSR system requiring online used fuel processing is tightly coupled with the performance of the used fuel process as the daily make-up fuel feed comes from the used fuel process operation. This tightly integrated system presents a unique challenge in the sense that a margin of error is small that the idealistic and/or loose assumptions from either side should not be overlooked. For example, as demonstrated in [22], the reprocessing involves trade-offs balancing performance metrics involving waste and product quality. Idealized assumption and requirement on the product quality may result in unreasonably poor waste quality such as high actinide partition to the waste stream.

Responding to this challenge, the chemistry group within the U.S. Department of Energy MSR Campaign is assigned to develop a model for the MSR system. The main purpose is to utilize the model for assessing the suitability of various used fuel processing schemes joined to various types of the MSRs. Also, this report aims to build a sound framework for better understanding the interplay between the components of the MSR system including uranium resources, the MSR, the UFP, and waste management.

The multidisciplinary nature of the reactor system comprised of heterogeneous system components calls for various mathematical modeling frameworks to model the whole system. An approach to resolve is to find the best mathematical framework for each component of the system and integrate all pieces in a unified developmental framework. Then, it is likely to involve multiple owners of the development pieces 
and the maintenance of the whole work is likely to be performed in a distributed manner (tight coordination and communication should be necessary). To quicken the development process and ease troubles coming from distributed maintenance, an ideal way to approach this problem is to have a common mathematical framework for addressing the whole system rather than having multiple pieces of technology requiring interpretation to execute the whole system. To this end, a unified theoretical framework for integrating the various components of the MSR system is desirable. The proposed framework in this report aims to approximate and integrate all components with a unified mathematical framework, a discrete-time linear system [23]. The goal is to provide a framework that should allow seamless component integration with acceptable sacrifice on the fidelity of the model. An example of an abstract MSR system is given to illustrate the effectiveness of the proposed theoretical framework.

\section{REACTOR SYSTEM MODEL}

A reactor system involves two key components: the reactor and the UFP.

The diagram given in Figure 1 gives the system material flow between these two components.

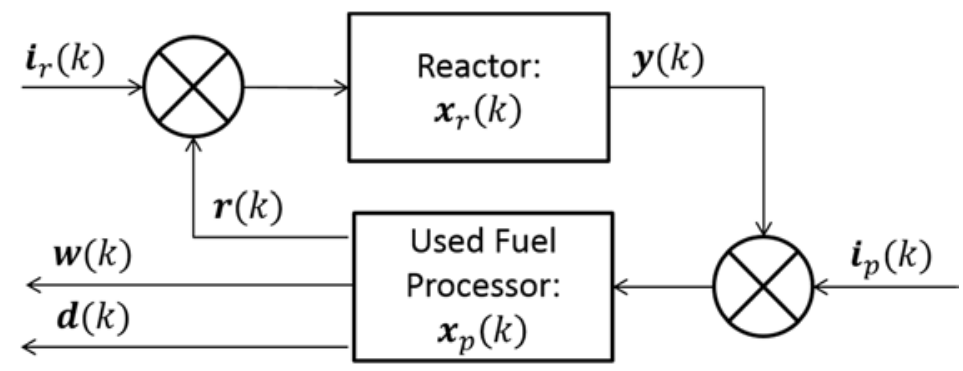

Figure 1. Reactor system.

The material streams and system states in Figure 1 represent the following. Note that the dimension of vector, $N$, represents the number of states in the system where the individual state holds information on a nuclide and its phase. Depending on the implementation details, further information may be included such as nuclide location in the system.

- $\quad x_{r}(k) \in \mathrm{R}^{N}$ : This represents the reactor inventory at the $k^{\text {th }}$ step post irradiation and prior to discharge

- $\quad x_{p}(k) \in \mathrm{R}^{N}$ : This represents the UFP inventory at the $k^{\text {th }}$ step post chemical processing and prior to discharge

- $\quad i_{r}(k) \in \mathrm{R}^{N}$ : This stream represents the external feed materials to the reactor at the $k^{\text {th }}$ step. Depending on the type of reactor and the adopted fissile material, this stream can vary from thorium, natural or depleted uranium, enriched uranium, and weapon grade plutonium.

- $\quad i_{p}(k) \in \mathrm{R}^{N}$ : This stream represents the chemical agents for the used fuel processing system. A wide array of technologies can be used for realizing the UFP. This material stream includes but is not limited to gaseous fluoride, gaseous chloride, thorium, uranium, and reactive metals.

- $\quad y(k) \in \mathrm{R}^{N}$ : This stream represents the discharged used fuel inventory from the reactor at the $k^{\text {th }}$ step. In the MSR system, this stream includes off gas fission product and a partial inventory of the molten salt fuel. 
- $r(k) \in \mathrm{R}^{N}$ : This stream represents the returned material stream from the UFP to the reactor. A typical material for this stream is the recovered actinides in an appropriate phase to be added to the reactor.

- $\quad w(k) \in \mathrm{R}^{N}$ : This stream represents the waste stream. These streams include fission products, off gas, and process waste materials incurred from the treatment of the used fuel at the used fuel process system.

- $\quad d(k) \in \mathrm{R}^{N}$ : This stream represents the product stream (e.g., excess fissile material). This stream is reserved for channeling the excess fissile material in case the reactor is operated as a fissile material breeder.

It is useful to look at the system from the perspective of material flow dependency. The simplest system option is the "once through" option. In this scenario, the input feed to the reactor does not come from its own discharge stream. That is, for all $k$,

$$
r(k)=\emptyset
$$

The "spent fuel" from the reactor may or may not be treated in the processing facility for the purpose of effective deposition to the repository. Typical reactor types promoting the once through option maximize the life of the fuels by irradiating the fuel as much as possible.

The discharge stream from the reactor holds a significant quantity of the actinides. The concept of used fuel recycling is to design the reactor to receive the actinides from its own discharge stream and reuse in its reactor operation. The UFP partitions the discharge stream into three streams: the waste stream holding the fission products, the product discharge stream holding the excess fissile actinides, and the feedback stream holding the recycled actinides.

\section{REACTOR CORE MODEL}

The reactor operation model proposed in this report is based on recursion. The adopted model uses a discretized time step and a recursive difference equation rather than dealing with continuous time directly with derivative. Note that a small discretized time step is analogous to a high frequency sampler, which should approximate the underlying dynamics with high precision. However, too finely chopped a time step incurs computational burdens when a significant number of recursions should be executed, for instance, to examine the state of equilibrium. Thus, for choosing a unit time step, one may want to find the coarsest time step to alleviate computational burden while approximation with discretization does not sacrifice the validity of the numerical results generated with the model.

The recursion in Equation (2) capturing the material flow around the reactor in Figure 1 represents reactor operation over a unit operation time.

$$
x_{r}(k+1)=P_{r}(k)\left(x_{r}(k)-y(k)+r(k)+i_{r}(k)\right)
$$

At time-step $k$, the reactor discharges a part of the inventory to the UFP represented with $y(k)$ while receiving the recycled material stream from the UFP $r(k)$ and exogenous feed stream $i_{r}(k)$. The discharged materials at the $k^{\text {th }}$ step operation are modeled as a linear function of the reactor inventory shown in Equation (3). 


$$
y(k)=Y(k) x_{r}(k)
$$

The diagonal entries of $Y(k) \in \mathrm{R}^{N \times N}$ represent the extent of the discharge of the nuclides from the reactor. For the MSR system, with the homogenization assumption of the fuel salt, all diagonal values corresponding to the nuclides of the salt phase should find the identical number. Other nuclides with different phases such as noble gas species may find a numeric different than the numeric assigned to represent the extent of salt phase discharge.

The combined reactor inventory at the time step $k, x_{r}(k)-y(k)+r(k)+i_{r}(k)$, undergoes irradiation for a unit time period. The transmutation matrix $P_{r}(k)$ represents the irradiation operation performed at the time step $k$ over a unit time period.

The first principle of the reactor physics can illustrate the entries of the transmutation matrix $P_{r}(k)$.

The Bateman framework given in (4) is a widely used set of differential equations describing the evolution of the reactor material inventory under irradiation.

$$
\dot{x}_{i}=-\left(\lambda_{i}+\sigma_{i} \phi\right) x_{i}+\sum_{j \neq i}\left(\lambda_{j \rightarrow i}+\sigma_{j \rightarrow i} \phi\right) x_{j}
$$

where

- $\quad x_{i}$ : nuclide $i$ concentration

- $\lambda_{i}$ : decay constant of isotope $i$

- $\phi$ : neutron flux

- $\sigma_{j \rightarrow i}$ : the cross section of the production of nuclide $i$ due to a neutron capture by nuclide $j$

- $\lambda_{j \rightarrow i}$ : decay parameter from $\mathrm{j}$ to $\mathrm{i}$

- $\sigma_{i}$ : the cross section of nuclide $i$

Let's denote

$$
x(t)=\left[\begin{array}{c}
x_{1}(t) \\
\vdots \\
x_{n}(t)
\end{array}\right]
$$

Then, Equation (4) can be written in a vector form as

$$
\dot{x}(t)=P x(t) \text { with } x(0)
$$

where

$$
P:=\left(\begin{array}{cccc}
-\lambda_{1}-\sigma_{1} \phi & \lambda_{2 \rightarrow 1}+\sigma_{2 \rightarrow 1} \phi & \cdots & \lambda_{n \rightarrow 1}+\sigma_{n \rightarrow 1} \phi \\
\lambda_{1 \rightarrow 2}+\sigma_{1 \rightarrow 2} \phi & -\lambda_{2}-\sigma_{2} \phi & \cdots & \lambda_{n \rightarrow 2}+\sigma_{n \rightarrow 2} \phi \\
\vdots & \vdots & \ddots & \vdots \\
\lambda_{1 \rightarrow n}+\sigma_{1 \rightarrow n} \phi & \lambda_{2 \rightarrow n}+\sigma_{2 \rightarrow n} \phi & \cdots & -\lambda_{n}-\sigma_{n} \phi
\end{array}\right)
$$


The mixing effect of the fuel salt in the MSR system may provide a lower level of heterogeneity of nuclide concentration. However, in general, the nuclide concentration depends on the coordinate of the reactor. A further complication of solving the Bateman equations comes from the neutron flux $\phi$ depending on location, nuclide concentration inventory, and neutron energy spectrum. Thus, the problem is typically addressed numerically when a high fidelity solution is required such as licensing a reactor design.

However, often the irradiation calculation is approximated with the point depletion solution by assuming the discretized neutron energy spectrum. Identifying the appropriate transmutation matrix is crucial for this approach.

In the chemistry group, the objective of developing the MSR system model is not in providing the most sophisticated reactor simulation tool but in identifying a suitable used fuel processing scheme for a given set of representative reactors. Thus, the initial stage of the development shall utilize the point depletion solution for the reactor component. Once the framework is established, the MSR Campaign chemistry group shall seek a more refined reactor counterpart to provide more accurate numerical results.

The solution of the above Bateman framework concerning the point depletion is given as Equation (8), where one only needs to evaluate an exponential matrix to assess the inventory at time $t$ given the initial inventory.

$$
x(t)=\exp (P t) x(0)
$$

Expressing the above solution with respect to time increments gives

$$
x(t+\Delta t)=\exp (P \Delta t) x(t)
$$

Recall Equation (2) given for the reactor operation. Then, if the phases of nuclides are ignored, one can see that

$$
P_{r}(k)=\exp (P \Delta t)
$$

Thus, simply specifying the unit time step $\Delta t$ gives the transmutation matrix $P_{r}(k)$.

Ranges of approaches exist to solve the Bateman equations such as deriving analytical solutions [24, 25] and exponential matrix approximations [26], etc. For now, rather than exhausting the literature addressing the prescribed problem, let us simply comment that sufficient attention has been given to the problem and the solution strategy should be readily available.

\section{USED FUEL PROCESS MODEL}

Like its reactor counterpart, the UFP operation model proposed in this report is also based on recursion. Equation (11) recursive model capturing the material flows in Figure 1 represents the used fuel process operation over a unit operation time.

$$
x_{p}(k+1)=P_{p}(k) \cdot\left(x_{p}(k)-r(k)-w(k)-d(k)+y(k)+i_{p}(k)\right)
$$


At time step $k$, the used fuel process discharges a part of the processed inventory to the reactor represented with $r(k)$. The UFP also discharges the process waste, denoted by $w(k)$, which is typically the separated fission products. In the case that the reactor is operated in a "breeder" mode, the net creation of fissile nuclides is positive during operation and the excess fissile inventory needs to be discharged from the system. This excess stream is to be stored for initiating the new reactor and denoted by $d(k)$ in the above equation.

Regarding the incoming material streams, the discharged reactor inventory $y(k)$ reports to the UFP along with the exogenous chemical agent stream $i_{p}(k)$ that is required to process the used fuel inventory accumulated in the UFP.

The recycled materials to the reactor at the $k^{\text {th }}$ step operation are expressed in Equation (12) with $R(k) \in \mathrm{R}^{N \times N}$.

$$
r(k)=R(k) x_{p}(k)
$$

The diagonal entries of $R(k)$ represent the extent of the nuclide extraction for the purpose of recycling with the deployed chemical separation scheme. Ideally, the MSR system stream should be the actiniderich salt phase with minimal partition of the lanthanides.

The waste stream exiting the used fuel process at the $k^{\text {th }}$ step operation is expressed in Equation (13) with $W(k) \in \mathrm{R}^{N \times N}$.

$$
w(k)=W(k) x_{p}(k)
$$

The diagonal entries of $W(k)$ represent the extent of the nuclide separation for the purpose of waste disposition with the deployed chemical separation scheme. Ideally, in the MSR system, the stream should be the lanthanide rich phase with minimal partition of the actinides. This stream also includes the off-gas phase holding noble gas species discharged from the reactor.

The excess materials exiting from the used fuel process at the $k^{\text {th }}$ step operation are expressed in Equation (14) with $D(k) \in \mathrm{R}^{N \times N}$.

$$
d(k)=D(k) x_{p}(k)
$$

The diagonal entries of $D(k)$ represent the extent of the nuclide extraction for the purpose of discharging the excess fissile materials with the deployed chemical separation scheme. In the case that a part of the recycled stream is rationed out as the excess fissile material discharge, the following relation should hold with $c(k) \in \mathrm{R}$.

$$
D(k)=c(k) R(k)
$$

The combined used fuel process inventory at the time step $k, x_{p}(k)-r(k)-w(k)-d(k)+y(k)+$ $i_{p}(k)$, undergoes the suite of chemical treatments. The treatment matrix $P_{p}(k)$ represents the chemical treatment operation performed at the time step $k$ over a unit time period.

Chemical treatment of the used fuel may involve phase changes (e.g., from salt to metal) and the corresponding separation factor. In fact, a suite of the proposed chemical treatment processes for the MSR 
system involve the contact of the molten metal and the molten salt to take advantage of the separation behaviors incurred from relative material stabilities with respect to the involved phases. The subjected materials undergo phase changes depending on their relative stabilities in the involved phases. For example, Equation (16) gives the partitioning behavior between uranium and cerium species, which commonly appear in the group actinide recovery process in the context of uranium based metal fuel reprocessing.

$$
\mathrm{UCl}_{3}+\mathrm{Ce}(\mathrm{Cd}) \leftrightarrow \mathrm{CeCl}_{3}+\mathrm{U}(\mathrm{Cd})
$$

The separation factor illustrating the extent of partition among these species can be defined with Equation (17). This is a useful thermodynamic value appearing frequently in many separation system applications.

$$
S F_{C e \mid U}=\frac{x_{C e, \text { salt }} x_{U, \text { metal }}}{x_{C e, \text { metal }}, x_{U, \text { salt }}}
$$

Note that the above separation factor is not stationary in general but the range of variation of this thermodynamic quantity is not likely to be significant [27]. For the purpose of modeling the MSR system, the separation factor will be approximated as a constant.

Typically, the process matrix $P_{p}(k)$ is realized with the nontrivial combination of various unit process separation performances and operational choices. An important factor determining the partitioning and separation performance embedded in the process matrix $P_{p}(k)$ is the balance between separation performance and process waste.

Note that the combined inventory of the used fuel process undergoes decay for a unit time period. This is particularly important for the used fuel process embedded in the MSR system as the used fuel does not undergo the extended cooling time prior to being subjected to chemical treatment. Thus, the process matrix $P_{p}(k)$ should embed the isotope decay functionality along with the partitioning and separation functionalities.

Comparing to the transmutation matrix discussed in the previous section, the implementation of decay functionality in the process matrix is simple as the point depletion of the Bateman equation with zero flux should give the decayed composition of the UFP inventory. That is,

$$
P_{d}=\exp \left(P_{\phi=0} \Delta t\right)
$$

where

$$
P_{\phi=0}:=\left(\begin{array}{cccc}
-\lambda_{1} & \lambda_{2 \rightarrow 1} & \cdots & \lambda_{n \rightarrow 1} \\
\lambda_{1 \rightarrow 2} & -\lambda_{2} & \cdots & \lambda_{n \rightarrow 2} \\
\vdots & \vdots & \ddots & \vdots \\
\lambda_{1 \rightarrow n} & \lambda_{2 \rightarrow n} & \cdots & -\lambda_{n}
\end{array}\right)
$$

Also, the process matrix should reflect the partitioning and separation functionality represented with the matrix $P_{S}(k)$. The complication is that these two phenomena occur concurrently. An approach resolving concurrency is to approximate the phenomena by serialization that the UFP inventory undergoes decay first (represented with operation matrix $P_{d}(k)$ ) and then the separation and partition afterward (represented with operation matrix $P_{s}(k)$ ). Then, the process matrix can be expressed as 


$$
P_{P}(k)=P_{S}(k) P_{d}(k)
$$

Reversing the above sequence can be conceived as an approximation as well. Then the process matrix is expressed as

$$
P_{P}(k)=P_{d}(k) P_{s}(k)
$$

\section{INTEGRATION OF TWO SYSTEM COMPONENTS}

The tasks of identifying a specific numeric for the matrixes given in the previous sections are underway within the campaign. The close collaboration between the reactor group and the chemistry group should result in suitable and meaningful outcomes with minimal effort once the framework is accepted within the campaign.

The framework given in the previous sections is useful for simulating the process scenarios with the identified matrices. Another notable of the framework given in the previous sections is that it allows a further mathematical analysis of the structure of the reactor system without a specific numeric. Replacing the involved material stream terms in the system recursion equations results in Equations (22-23).

$$
\begin{gathered}
x_{r}(k+1)=P_{r}(k)\left((I-Y(k)) x_{r}(k)+R(k) x_{p}(k)+i_{r}(k)\right) \\
x_{p}(k+1)=P_{p}(k) \cdot\left((I-R(k)-W(k)-D(k)) x_{p}(k)+Y(k) x_{r}(k)+i_{p}(k)\right)
\end{gathered}
$$

Merging the above reactor and UFP states, the recursion on the combined system state is given as Equation (24).

$$
\left[\begin{array}{l}
x_{r}(k+1) \\
x_{p}(k+1)
\end{array}\right]=A(k)\left[\begin{array}{l}
x_{r}(k) \\
x_{p}(k)
\end{array}\right]+B(k)\left[\begin{array}{l}
i_{r}(k) \\
i_{p}(k)
\end{array}\right]
$$

where

$$
A(k):=\left[\begin{array}{cc}
P_{r}(k)(I-Y(k)) & P_{r}(k) R(k) \\
P_{p}(k) Y(k) & P_{p}(k)(I-R(k)-W(k)-D(k))
\end{array}\right]
$$

and

$$
B(k):=\left[\begin{array}{cc}
P_{r}(k) & 0 \\
0 & P_{p}(k)
\end{array}\right]
$$

Assume that parametric matrices are all invariant hereafter for this section. This is a reasonable assumption for equilibrium analysis of the system as the entries of the matrices associated with system operational parameters should converge as the system approaches its steady state. With stationary $A$ and $B$ matrices, the system state is expressed as the sum of the initial state attenuation and the weighted sum of the exogenous input streams. 


$$
\left[\begin{array}{l}
x_{r}(k+1) \\
x_{p}(k+1)
\end{array}\right]=A^{k+1}\left[\begin{array}{l}
x_{r}(0) \\
x_{p}(0)
\end{array}\right]+\sum_{m=0}^{k} A^{k-m} B\left[\begin{array}{l}
i_{r} \\
i_{p}
\end{array}\right]
$$

Then, the steady state can be expressed in Equation (28).

$$
\lim _{k \rightarrow \infty}\left[\begin{array}{l}
x_{r}(k+1) \\
x_{p}(k+1)
\end{array}\right]=\lim _{k \rightarrow \infty} A^{k+1}\left[\begin{array}{l}
x_{r}(0) \\
x_{p}(0)
\end{array}\right]+\lim _{k \rightarrow \infty} \sum_{m=0}^{k} A^{k-m} B\left[\begin{array}{l}
i_{r} \\
i_{p}
\end{array}\right]
$$

Assuming that $(I-A)$ is invertible and the exogenous input streams are invariant, then Equation (28) becomes Equation (29).

$$
\lim _{k \rightarrow \infty}\left[\begin{array}{l}
x_{r}(k+1) \\
x_{p}(k+1)
\end{array}\right]=\lim _{k \rightarrow \infty} A^{k+1}\left[\begin{array}{l}
x_{r}(0) \\
x_{p}(0)
\end{array}\right]+(I-A)^{-1} B\left[\begin{array}{l}
i_{r} \\
i_{p}
\end{array}\right]
$$

A likely assumption on the non-empty discharge for all elements and the mass preservation principle should give the convergence of the initial state attenuation to zero in Equation (30).

$$
\lim _{k \rightarrow \infty} A^{k}\left[\begin{array}{l}
x_{r}(0) \\
x_{p}(0)
\end{array}\right]=0
$$

Then, the expression for the steady-state of the system becomes

$$
\lim _{k \rightarrow \infty}\left[\begin{array}{l}
x_{r}(k) \\
x_{p}(k)
\end{array}\right]=(I-A)^{-1} B\left[\begin{array}{l}
i_{r} \\
i_{p}
\end{array}\right]
$$

Once the steady state of the system is identified, the steady-state material streams can be expressed as

$$
\begin{gathered}
\lim _{k \rightarrow \infty} y(k)=Y \lim _{k \rightarrow \infty} x_{r}(k) \\
\lim _{k \rightarrow \infty} r(k)=R \lim _{k \rightarrow \infty} x_{p}(k) \\
\lim _{k \rightarrow \infty} w(k)=W \lim _{k \rightarrow \infty} x_{p}(k) \\
\lim _{k \rightarrow \infty} d(k)=D \lim _{k \rightarrow \infty} x_{p}(k)
\end{gathered}
$$

\section{ILLUSTRATIVE EXAMPLE OF MODEL INTEGRATION}

This section gives a simple example to illustrate the proposed structure intended to be used for developing a simulation tool for the MSR system. First, define the reactor state includingthe four components as below: 


$$
x_{r}(k)=\left[\begin{array}{c}
x_{f i s s i l e, r}(k) \\
x_{f e r t i l e, r}(k) \\
x_{f i s s i o n, r}(k) \\
x_{\text {offgas }, r}(k)
\end{array}\right]
$$

Each component represents the following.

- $\quad x_{\text {fissile,r }}(k)$ : Fissile material inventory in reactor at time $\mathrm{k}$

- $\quad x_{\text {fertile,r }}(k)$ : Fertile material inventory in reactor at time $\mathrm{k}$

- $\quad x_{\text {fission,r }}(k)$ : Fission material inventory in reactor at time $\mathrm{k}$

- $\quad x_{o f f g a s, r}(k)$ : Off-gas material inventory in reactor at time $\mathrm{k}$.

Assume the reactor performs the following operations for a given unit operation time.

- Fission consumes $1 \%$ of fissile material: $P_{r}(1,1)=0.99$

- $\quad 0.9 \%$ of fissile material converts to non-volatile fission products: $P_{r}(3,1)=0.009$

- $\quad 0.1 \%$ of fissile material converts to off gas fission products: $P_{r}(4,1)=0.001$

- Transmutation consumes $0.1 \%$ of fertile material: $P_{r}(2,2)=0.999$

- $0.1 \%$ of fertile material transmutes to fissile material: $P_{r}(1,2)=0.001$.

$$
P_{r}=\left[\begin{array}{cccc}
0.99 & 0.001 & 0 & 0 \\
0 & 0.999 & 0 & 0 \\
0.009 & 0 & 1 & 0 \\
0.001 & 0 & 0 & 1
\end{array}\right]
$$

The reactor discharge operation performs the following set of operations for a given unit operation time.

- $\quad$ Reactor discharges $\mathrm{x} \%$ of fissile inventory to UFP: $Y(1,1)=0.01 x$

- Reactor discharges $\mathrm{x} \%$ of fertile inventory to UFP: $Y(2,2)=0.01 x$

- Reactor discharges $\mathrm{x} \%$ of fission product to UFP: $Y(3,3)=0.01 x$

- $\quad$ Reactor discharges $99 \%$ of off gas inventory to UFP: $Y(4,4)=0.99$.

$$
Y=\left[\begin{array}{cccc}
0.01 x & 0 & 0 & 0 \\
0 & 0.01 x & 0 & 0 \\
0 & 0 & 0.01 x & 0 \\
0 & 0 & 0 & 0.99
\end{array}\right]
$$

The UFP performs the following operations

- $\quad$ Returns $99 \%$ of UFP fissile inventory to the reactor: $R(1,1)=0.99$

- Returns 99\% of UFP fertile inventory to the reactor: $R(2,2)=0.99$

- Returns 9.9\% of UFP fission product inventory to the reactor: $R(3,3)=0.099$

- Returns $0.1 \%$ of UFP off gas inventory to the reactor: $R(4,4)=0.001$. 


$$
R=\left[\begin{array}{cccc}
0.99 & 0 & 0 & 0 \\
0 & 0.99 & 0 & 0 \\
0 & 0 & 0.099 & 0 \\
0 & 0 & 0 & 0.001
\end{array}\right]
$$

The assumed UFP operations are

- Reports $0.1 \%$ of UFP fissile inventory to the waste stream: $W(1,1)=0.001$

- Reports $0.2 \%$ of UFP fertile inventory to the waste stream: $W(2,2)=0.002$

- $\quad$ Directs $90 \%$ of fission product inventory from UFP to the waste stream: $W(3,3)=0.9$

- $\quad$ Directs $99.8 \%$ of off gas inventory from UFP to the waste stream: $W(4,4)=0.998$.

$$
W=\left[\begin{array}{cccc}
0.001 & 0 & 0 & 0 \\
0 & 0.002 & 0 & 0 \\
0 & 0 & 0.9 & 0 \\
0 & 0 & 0 & 0.998
\end{array}\right]
$$

The assumed UFP operations are

- Reports $0.9 \%$ of UFP fissile inventory to the excess product stream: $D(1,1)=0.009$

- Reports $0.8 \%$ of UFP fertile inventory to the excess product stream: $D(2,2)=0.008$

- Reports $0.1 \%$ of UFP fission product inventory to the excess product stream: $D(3,3)=0.001$

- Reports $0.1 \%$ of UFP off gas inventory to the excess product stream: $D(4,4)=0.001$.

$$
D=\left[\begin{array}{cccc}
0.009 & 0 & 0 & 0 \\
0 & 0.008 & 0 & 0 \\
0 & 0 & 0.001 & 0 \\
0 & 0 & 0 & 0.001
\end{array}\right]
$$

The reactor inventory begins with

$$
x_{r}(0)=\left[\begin{array}{l}
x_{r, \text { fissile }}(0) \\
x_{r, \text { fertile }}(0) \\
x_{r, \text { fission }}(0) \\
x_{r, \text { offgas }}(0)
\end{array}\right]=\left[\begin{array}{c}
10 \\
90 \\
0 \\
0
\end{array}\right]
$$

The used fuel processor inventory at the onset is

$$
x_{p}(0)=\left[\begin{array}{l}
x_{p, \text { fissile }}(0) \\
x_{p, \text { fertile }}(0) \\
x_{p, \text { fission }}(0) \\
x_{p, \text { offgas }}(0)
\end{array}\right]=\left[\begin{array}{l}
0 \\
0 \\
0 \\
0
\end{array}\right]
$$

The exogenous input to the reactor is assumed to be all fertile species and the quantity is determined to steady the total reactor inventory. 


$$
i_{r}=\left[\begin{array}{c}
0 \\
i_{\text {fertile }} \\
0 \\
0
\end{array}\right]
$$

In general, it is likely to involve exogenous chemical agents such as metallic thorium and lithium along with various gas species to operate the used fuel processor. For this example illustrating the framework of the model, the exogeneous chemical agent stream is assumed to be null.

$$
i_{p}=\left[\begin{array}{l}
0 \\
0 \\
0 \\
0
\end{array}\right]
$$

Suppose that the reactor discharges $1 \%$ of inventory each unit time operation. Then, with $i_{r}=$ $\left[\begin{array}{llll}0 & 0.092 & 0 & 0\end{array}\right]^{T}$, the system reaches an equilibrium maintaining the total inventory of the reactor at 100 . Figure 2 provides a snapshot of the scenario discussed.

$$
\begin{aligned}
& P_{r}=\left[\begin{array}{cccc}
0.99 & 0.001 & 0 & 0 \\
0 & 0.999 & 0 & 0 \\
0.009 & 0 & 1 & 0 \\
0.001 & 0 & 0 & 1
\end{array}\right]
\end{aligned}
$$

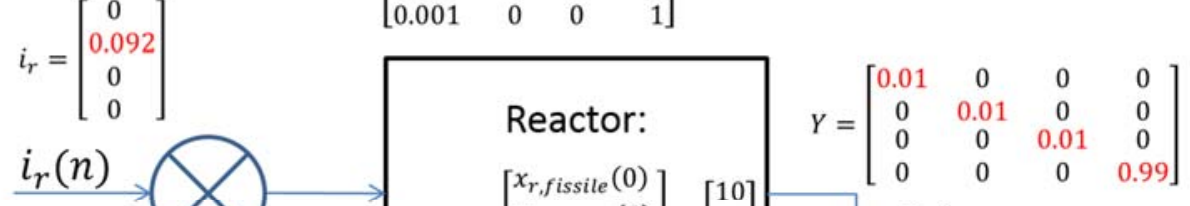

$$
\begin{aligned}
& R=\left[\begin{array}{cccc}
0.99 & 0 & 0 & 0 \\
0 & 0.99 & 0 & 0 \\
0 & 0 & 0.099
\end{array} \quad x_{r}(0)=\left[\begin{array}{l}
x_{r}, \text { fistite }(0) \\
x_{r, \text { fission }}(0) \\
x_{r, \text { off gas }}(0)
\end{array}\right]=\left[\begin{array}{c}
10 \\
90 \\
0 \\
0
\end{array}\right] \quad y(n)\right. \\
& \left.\begin{array}{cccc}
0 & 0 & 0.099 & 0 \\
0 & 0 & 0 & 0.001
\end{array}\right] \quad i_{p}=\left[\begin{array}{l}
0 \\
0 \\
0 \\
0
\end{array}\right]
\end{aligned}
$$

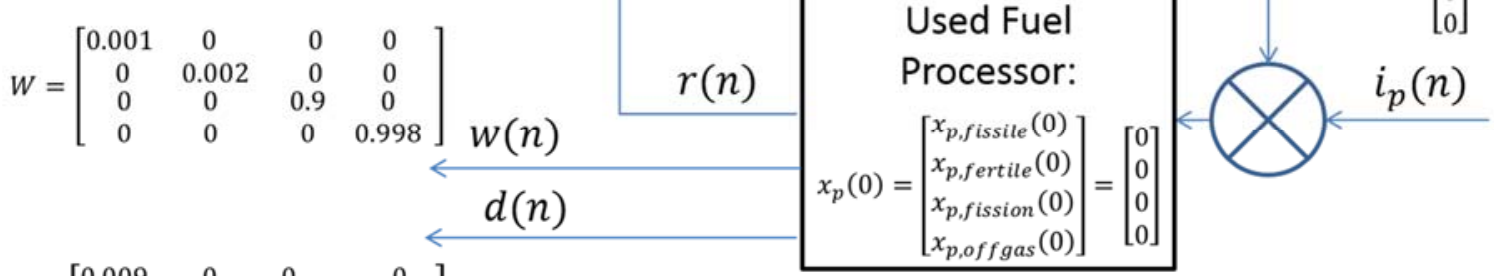

$$
\begin{aligned}
& D=\left[\begin{array}{cccc}
0.009 & 0 & 0 & 0 \\
0 & 0.008 & 0 & 0 \\
0 & 0 & 0.001 & 0 \\
0 & 0 & 0 & 0.001
\end{array}\right] \quad P_{p}=\left[\begin{array}{llll}
1 & 0 & 0 & 0 \\
0 & 0 & 0 & 0 \\
0 & 0 & 1 & 0 \\
0 & 0 & 0 & 1
\end{array}\right]
\end{aligned}
$$

Figure 2. Operation matrices for 1\% reactor inventory discharge scenario.

Table 1 gives the steady-state material streams of the scenario illustrated in Figure 2. The fission product build up is almost equivalent to the fissile material inventory in the reactor. This may not be an acceptable equilibrium mode for the MSR system. 
Table 1. Steady-state material inventories and flows with $1 \%$ reactor inventory discharge.

\begin{tabular}{|c|c|c|c|c|c|c|}
\hline $\begin{array}{c}1 \% \text { Inv. } \\
\text { Discharge }\end{array}$ & $\begin{array}{c}\text { Reactor } \\
x_{r}\end{array}$ & $\begin{array}{c}\text { UFP } \\
x_{p}\end{array}$ & $\begin{array}{c}\text { Discharge } \\
y\end{array}$ & $\begin{array}{c}\text { Recycle } \\
r\end{array}$ & $\begin{array}{c}\text { Waste } \\
w\end{array}$ & $\begin{array}{c}\text { Excess } \\
d\end{array}$ \\
\hline Fissile & $8.282 \mathrm{E}+00$ & $8.282 \mathrm{E}-02$ & $8.282 \mathrm{E}-02$ & $8.200 \mathrm{E}-02$ & $8.282 \mathrm{E}-05$ & $7.454 \mathrm{E}-04$ \\
\hline Fertile & $8.356 \mathrm{E}+01$ & $8.356 \mathrm{E}-01$ & $8.356 \mathrm{E}-01$ & $8.272 \mathrm{E}-01$ & $1.671 \mathrm{E}-03$ & $6.685 \mathrm{E}-03$ \\
\hline Fission & $8.272 \mathrm{E}+00$ & $8.272 \mathrm{E}-02$ & $8.272 \mathrm{E}-02$ & $8.190 \mathrm{E}-03$ & $7.445 \mathrm{E}-02$ & $8.272 \mathrm{E}-05$ \\
\hline Off gas & $8.374 \mathrm{E}-03$ & $8.290 \mathrm{E}-03$ & $8.290 \mathrm{E}-03$ & $8.290 \mathrm{E}-06$ & $8.273 \mathrm{E}-03$ & $8.290 \mathrm{E}-06$ \\
\hline
\end{tabular}

To reduce the fission product build up in the reactor inventory, the discharge rate of the reactive inventory is doubled and the steady-state material streams are recalculated below. In order to maintain the reactor steady-state inventory at 100, the exogenous feed for the reactor is required to have $i_{r}=\left[\begin{array}{lllll}0 & 0.105 & 0 & 0\end{array}\right]^{T}$. Figure 3 gives a snapshot of the scenario discussed.

$$
\begin{aligned}
& P_{r}=\left[\begin{array}{cccc}
0.99 & 0.001 & 0 & 0 \\
0 & 0.999 & 0 & 0 \\
0.009 & 0 & 1 & 0 \\
0.001 & 0 & 0 & 1
\end{array}\right] \\
& i_{r}=\left[\begin{array}{c}
0 \\
0.105 \\
0 \\
0
\end{array}\right]
\end{aligned}
$$

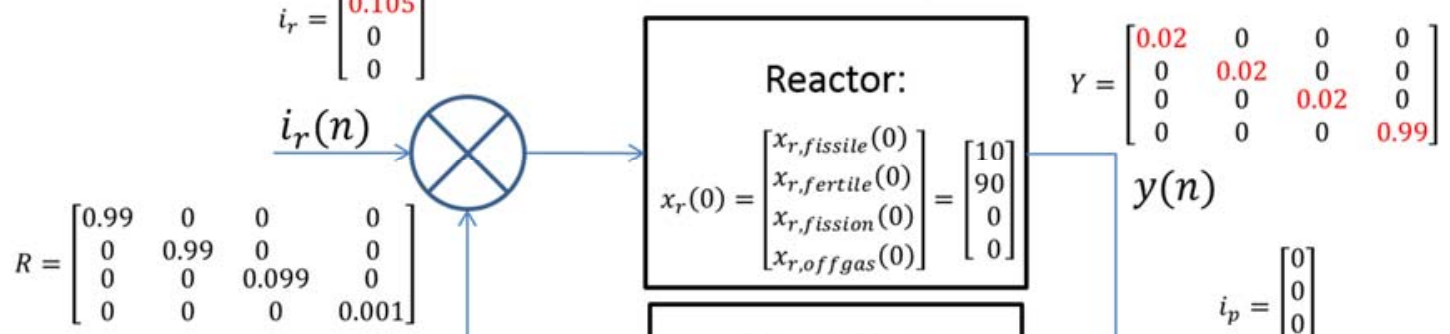

$$
\begin{aligned}
& \begin{aligned}
W=\left[\begin{array}{cccc}
0.001 & 0 & 0 & 0 \\
0 & 0.002 & 0 & 0 \\
0 & 0 & 0.9 & 0 \\
0 & 0 & 0 & 0.998
\end{array}\right] & w(n) \quad r(n) \\
&
\end{aligned} \\
& D=\left[\begin{array}{cccc}
0.009 & 0 & 0 & 0 \\
0 & 0.008 & 0 & 0 \\
0 & 0 & 0.001 & 0 \\
0 & 0 & 0 & 0.001
\end{array}\right] \\
& i_{p}=\left[\begin{array}{l}
0 \\
0 \\
0 \\
0
\end{array}\right] \\
& \text { Processor: } \\
& x_{p}(0)=\left[\begin{array}{l}
x_{p, \text { fissile }}(0) \\
x_{p, \text { fertile }}(0) \\
x_{p, \text { fission }}(0) \\
x_{p, \text { offgas }}(0)
\end{array}\right]=\left[\begin{array}{l}
0 \\
0 \\
0 \\
0
\end{array}\right] \\
& P_{p}=\left[\begin{array}{llll}
1 & 0 & 0 & 0 \\
0 & 0 & 0 & 0 \\
0 & 0 & 1 & 0 \\
0 & 0 & 0 & 1
\end{array}\right]
\end{aligned}
$$

Figure 3. Operation matrices for 2\% reactor inventory discharge scenario.

Table 2 gives the steady-state material streams of the scenario of $2 \%$ reactor inventory discharge illustrated in Figure 3. The fission product build up is nearly halved compared to the case of 1\% reactor inventory discharge per unit time. While the fission inventory is halved in the reactor, the steady-state fissile and fertile inventory discharges to the waste stream are doubled as a consequence. Also the required exogenous feed to maintain the reactor inventory shows a slight increase. 
Table 2. Steady-state material inventories and flows with $2 \%$ reactor inventory discharge.

\begin{tabular}{|c|c|c|c|c|c|c|}
\hline $\begin{array}{c}2 \% \text { Inv. } \\
\text { Discharge }\end{array}$ & $\begin{array}{c}\text { Reactor } \\
x_{r}\end{array}$ & $\begin{array}{c}\text { UFP } \\
x_{p}\end{array}$ & $\begin{array}{c}\text { Discharge } \\
y\end{array}$ & $\begin{array}{c}\text { Recycle } \\
r\end{array}$ & $\begin{array}{c}\text { Waste } \\
w\end{array}$ & $\begin{array}{c}\text { Excess } \\
d\end{array}$ \\
\hline Fissile & $8.582 \mathrm{E}+00$ & $1.716 \mathrm{E}-01$ & $1.716 \mathrm{E}-01$ & $1.699 \mathrm{E}-01$ & $1.716 \mathrm{E}-04$ & $1.545 \mathrm{E}-03$ \\
\hline Fertile & $8.743 \mathrm{E}+01$ & $1.749 \mathrm{E}+00$ & $1.749 \mathrm{E}+00$ & $1.731 \mathrm{E}+00$ & $3.497 \mathrm{E}-03$ & $1.399 \mathrm{E}-02$ \\
\hline Fission & $4.285 \mathrm{E}+00$ & $8.570 \mathrm{E}-02$ & $8.570 \mathrm{E}-02$ & $8.485 \mathrm{E}-03$ & $7.713 \mathrm{E}-02$ & $8.570 \mathrm{E}-05$ \\
\hline Off gas & $8.675 \mathrm{E}-03$ & $8.588 \mathrm{E}-03$ & $8.588 \mathrm{E}-03$ & $8.588 \mathrm{E}-06$ & $8.571 \mathrm{E}-03$ & $8.588 \mathrm{E}-06$ \\
\hline
\end{tabular}

To reduce the fission product build up in the reactor inventory further, the discharge rate of the reactive inventory is adjusted to $10 \%$ and the steady-state material streams are recalculated below. In order to maintain the reactor steady-state inventory at 100, the exogenous feed for the reactor is required to have $i_{r}=\left[\begin{array}{lllll}0 & 0.182 & 0 & 0\end{array}\right]^{T}$. Figure 4 gives a snapshot of the scenario discussed.

$$
\begin{aligned}
& P_{r}=\left[\begin{array}{cccc}
0.99 & 0.001 & 0 & 0 \\
0 & 0.999 & 0 & 0 \\
0.009 & 0 & 1 & 0 \\
0.001 & 0 & 0 & 1
\end{array}\right] \\
& i_{r}=\left[\begin{array}{c}
0 \\
0.182 \\
0 \\
0
\end{array}\right] \\
& \underline{i_{r}(n)} \\
& R=\left[\begin{array}{cccc}
0.99 & 0 & 0 & 0 \\
0 & 0.99 & 0 & 0 \\
0 & 0 & 0.099 & 0 \\
0 & 0 & 0 & 0.001
\end{array}\right] \\
& W=\left[\begin{array}{cccc}
0.001 & 0 & 0 & 0 \\
0 & 0.002 & 0 & 0 \\
0 & 0 & 0.9 & 0 \\
0 & 0 & 0 & 0.998
\end{array}\right] \\
& r(n) \\
& x_{r}(0)=\left[\begin{array}{l}
\text { Reactor: } \\
x_{r, \text { fissile }}(0) \\
x_{r, \text { fertile }}(0) \\
x_{r, \text { fission }}(0) \\
x_{r, \text { off gas }}(0)
\end{array}\right]=\left[\begin{array}{c}
10 \\
90 \\
0 \\
0
\end{array}\right] \\
& \begin{array}{l}
Y=\left[\begin{array}{cccc}
0.1 & 0 & 0 & 0 \\
0 & 0.1 & 0 & 0 \\
0 & 0 & 0.1 & 0 \\
0 & 0 & 0 & 0.99
\end{array}\right] \\
y(n)
\end{array}
\end{aligned}
$$

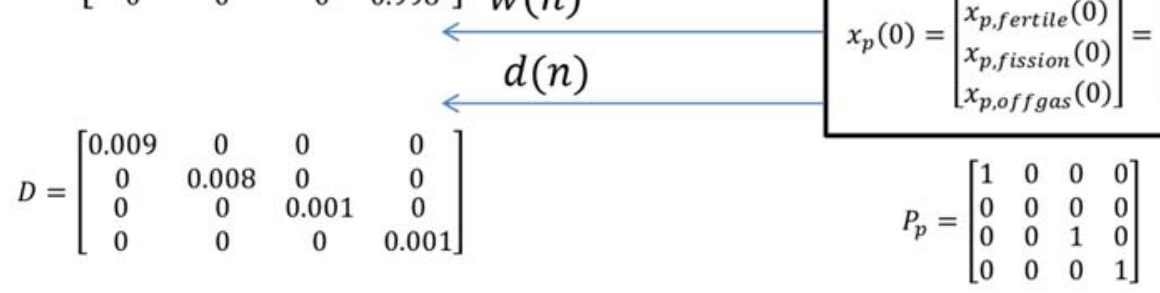

$$
\begin{aligned}
& x_{p}(0)=\left[\begin{array}{l}
x_{p, \text { fissile }}(0) \\
x_{p, \text { fertile }}(0) \\
x_{\text {p.fission }}(0)
\end{array}\right]=\left[\begin{array}{l}
0 \\
0 \\
0 \\
0
\end{array}\right]
\end{aligned}
$$

Figure 4. Operation matrices for $10 \%$ reactor inventory discharge scenario.

Table 3 gives the steady-state material streams of the scenario of $10 \%$ reactor inventory discharge illustrated in Figure 4. The fission product build up is reduced an order of magnitude compared to the case of $1 \%$ reactor inventory discharge per unit time and the steady-state fissile and fertile inventory discharges to the waste stream show an order of magnitude increase as a consequence. Also, the required exogenous feed to maintain the reactor inventory shows a significant increase. 
Table 3. Steady-state material inventories and flows with 10\% reactor inventory discharge.

\begin{tabular}{|c|c|c|c|c|c|c|}
\hline $\begin{array}{c}\text { 10\% Inv. } \\
\text { Discharge }\end{array}$ & $\begin{array}{c}\text { Reactor } \\
x_{r}\end{array}$ & $\begin{array}{c}\text { UFP } \\
x_{p}\end{array}$ & $\begin{array}{c}\text { Discharge } \\
y\end{array}$ & $\begin{array}{c}\text { Recycle } \\
r\end{array}$ & $\begin{array}{c}\text { Waste } \\
w\end{array}$ & $\begin{array}{c}\text { Excess } \\
d\end{array}$ \\
\hline Fissile & $8.284 \mathrm{E}+00$ & $8.284 \mathrm{E}-01$ & $8.284 \mathrm{E}-01$ & $8.202 \mathrm{E}-01$ & $8.284 \mathrm{E}-04$ & $7.456 \mathrm{E}-03$ \\
\hline Fertile & $9.095 \mathrm{E}+01$ & $9.095 \mathrm{E}+00$ & $9.095 \mathrm{E}+00$ & $9.004 \mathrm{E}+00$ & $1.819 \mathrm{E}-02$ & $7.276 \mathrm{E}-02$ \\
\hline Fission & $8.267 \mathrm{E}-01$ & $8.267 \mathrm{E}-02$ & $8.267 \mathrm{E}-02$ & $8.184 \mathrm{E}-03$ & $7.440 \mathrm{E}-02$ & $8.267 \mathrm{E}-05$ \\
\hline Off gas & $8.368 \mathrm{E}-03$ & $8.284 \mathrm{E}-03$ & $8.284 \mathrm{E}-03$ & $8.284 \mathrm{E}-06$ & $8.268 \mathrm{E}-03$ & $8.284 \mathrm{E}-06$ \\
\hline
\end{tabular}

\section{REMARKS AND FUTURE WORKS}

The following lists the planned short term development work to be performed during the remaining fiscal year and beyond.

- Identifying the transmutation matrix $P_{r}$, modeling the point depletion behavior of the MSR. This task will be performed with the aid of the reactor group in the campaign. SCALE (a comprehensive modeling and simulation suite for nuclear safety analysis and design developed and maintained by ORNL) software will be used to validate the developed MSR models.

- Identifying unit processes and assumed performance. This task will be performed with the aid of the chemistry group in the campaign. The completion of the task will result in the identification of the matrices $Y, P_{p}, R, D$, and $W$ for the used fuel process.

- Specifying reactor requirements (e.g., $\mathrm{Xr}$ and $\mathrm{Kr}$ concentration limits in the reactor, rare earth concentration limits in the reactor, and the required fissile isotope concentration requirements for reactor operation, etc.) and down-selecting the unit process technology based on the requirements.

\section{REFERENCE}

[1] Dolan, Thomas J., ed. Molten Salt Reactors and Thorium Energy, Woodhead Publishing, 2017.

[2] Bauman, H. F., G. W. Cunningham III, J. L. Lucius, H. T. Kerr, and C. W. Craven Jr. "ROD: A Nuclear and Fuel-Cycle Analysis Code for Circulating-Fuel Reactors.” ORNL/TM-3359, Oak Ridge National Laboratory (1971).

[3] Kee, C. W., and L. E. McNeese. “MRPP: multiregion processing plant code.” ORNL/TM-4210, Oak Ridge National Laboratory (1976).

[4] Bulmer, J. J. Fused Salt Fast Breeder: Reactor Design and Feasibility Study. Vol. 56, No. 8-204. United States Atomic Energy Commission, Technical Information Service Extension, 1957.

[5] Smith, J., and W. E. Simmons. "An Assessment of a 2500MWe Molten Chloride Salt Fast Reactor, AEEW-R956.” UKAEA Winfrith (1974). 
[6] Robertson, R. C., R. B. Briggs, O. L. Smith, and E. S. Bettis. ”Two-Fluid Molten-Salt Breeder Reactor Design Study (Status as of January 1, 1968).” ORNL/TM-4528, Oak Ridge National Laboratory (1970).

[7] Robertson, R.C. ”Conceptual Design Study of a Single-Fluid Molten-Salt Breeder Reactor.” ORNL/TM-4541, Oak Ridge National Laboratory (1971).

[8] Taube, M., and J. Ligou. "Molten plutonium chlorides fast breeder reactor cooled by molten uranium chloride.” Annals of Nuclear Science and Engineering 1, No. 4 (1974): 277-281.

[9] Heuer, D., E. Merle-Lucotte, M. Allibert, M. Brovchenko, V. Ghetta, and P. Rubiolo. “Towards the thorium fuel cycle with molten salt fast reactors.” Annals of Nuclear Energy 64 (2014): 421-429.

[10] Heuer, D., E. Merle-Lucotte, M. Allibert, Doligez, X., Ghetta, V. “Simulation tools and new developments of the molten salt fast reactor.” In: Contribution A0115, Proceedings of the European Nuclear Conference ENC2010, Barcelona, Spain, 2010.

[11] Nuttin, A., D. Heuer, A. Billebaud, R. Brissot, C. Le Brun, E. Liatard, J-M. Loiseaux et al. “Potential of thorium molten salt reactors detailed calculations and concept evolution with a view to large scale energy production.” Progress in nuclear energy 46, No. 1 (2005): 77-99.

[12] Doligez, X., D. Heuer, E. Merle-Lucotte, M. Allibert, and V. Ghetta. "Coupled study of the Molten Salt Fast Reactor core physics and its associated reprocessing unit.” Annals of Nuclear Energy 64 (2014): 430-440.

[13] Fiorina, C., M. Aufiero, A. Cammi, F. Franceschini, J. Krepel, L. Luzzi, K. Mikityuk, and M.E. Ricotti. "Investigation of the MSFR core physics and fuel cycle characteristics." Progress in Nuclear Energy 68 (2013): 153-168.

[14] Fiorina, C., D. Lathouwers, M. Aufiero, A. Cammi, C. Guerrieri, J. L. Kloosterman, L. Luzzi, and M. E. Ricotti. "Modelling and analysis of the MSFR transient behaviour." Annals of Nuclear Energy 64 (2014): 485-498.

[15] Sheu, R. J., C.H. Chang, C.C. Chao, and Y-WH Liu. "Depletion analysis on long-term operation of the conceptual Molten Salt Actinide Recycler \& Transmuter (MOSART) by using a special sequence based on SCALE6/TRITON.” Annals of Nuclear Energy 53 (2013): 1-8.

[16] Aufiero, M., A. Cammi, C. Fiorina, J. Leppänen, L. Luzzi, and M. E. Ricotti. “An extended version of the SERPENT-2 code to investigate fuel burn-up and core material evolution of the Molten Salt Fast Reactor.” Journal of Nuclear Materials 441, No. 1-3 (2013): 473-486.

[17] Xu, Z., P. Hejzlar, M. J. Driscoll, and M. S. Kazimi. “An Improved MCNP-ORIGEN Depletion Program (MCODE) and Its Verification for High-Burnup Applications.” PHYSOR 2002 (2002): 7-10.

[18] Ahmad, A., E. B. McClamrock, and A. Glaser. "Neutronics calculations for denatured molten salt reactors: Assessing resource requirements and proliferation-risk attributes.” Annals of Nuclear Energy 75 (2015): 261-267. 
[19] Jeong, Y., J. Park, H. Lee, and D. Lee. "Equilibrium core design methods for molten salt breeder reactor based on two-cell model.” Journal of Nuclear Science and Technology 53, No. 4 (2016): 529-536.

[20] Powers, J. J., T. J. Harrison, and J. C. Gehin. "A new approach for modeling and analysis of molten salt reactors using SCALE.” In: Proc. Int. Conf. Mathematics and Computational Methods Applied to Nuclear Science and Engineering (M\&C 2013), Sun Valley, Idaho, 2013

[21] Betzler, B.R., J.J. Powers, and W. Andrew. "Molten salt reactor neutronics and fuel cycle modeling and simulation with SCALE.” Annals of Nuclear Energy 101 (2017): 489-503.

[22] Yoo, T.-S. "Follow the MASTERS: A Discrete-Time Dynamic System Model for a Pyroprocessing Flowsheet.” International Pyroprocessing Research Conference (IPIC 2016), Jeje City, South Korea, 2016.

[23] Chen, Chi-Tsong. Linear system theory and design. Oxford University Press, Inc., 1998.

[24] Bateman, Harry. "The solution of a system of differential equations occurring in the theory of radioactive transformations.” In Proc. Cambridge Philos. Soc., Vol. 15, pp. 423-427. 1910.

[25] Cetnar, Jerzy. "General solution of Bateman equations for nuclear transmutations.” Annals of Nuclear Energy 33, No. 7 (2006): 640-645.

[26] Hermann, O. W., and R. M. Westfall. “ORIGEN-S: SCALE system module to calculate fuel depletion, actinide transmutation, fission product buildup and decay, and associated radiation source terms.” Vol. II, Sect. F7 of SCALE: A Modular Code System for Performing Standardized Computer Analyses for Licensing Evaluation, NUREG/CR-0200, Rev 6 (1995).

[27] Fredrickson, G. L., and T.-S. Yoo. "Analysis and modeling of the equilibrium behaviors of $\mathrm{U}$ and $\mathrm{Pu}$ in molten LiCl-KCl/Cd system at 500 C." Journal of Nuclear Materials 508 (2018): 51-62. 